\title{
eGovernment and Organizational Changes: Towards an Extended Governance Model
}

\author{
Elisabetta Raguseo $^{1}$ and Enrico Ferro ${ }^{2}$ \\ ${ }^{1}$ Politecnico di Torino, Corso Duca degli Abruzzi 24, 10129, Torino \\ elisabetta.raguseo@polito.it \\ ${ }^{2}$ Istituto Superiore Mario Boella, Via Pier Carlo Boggio 61, 10138, Torino \\ enrico.ferro@ismb.it
}

\begin{abstract}
Over the last decade the diffusion of Information Technologies has represented one of the main drivers of government reform. The adoption process of such technologies has posed significant challenges for public organizations. The aim of this paper is thus to look into the process of organizational change that public agencies have undergone, in order to single out its most salient characteristics, such as understanding changes in the adoption of technologies, in organizational choices, in skill needs and in customer-public administrations relationship. On the one hand, organizations are gradually opening up their institutional boundaries in order to proactively answer to environmental changes. On the other hand, citizens play an increasing role in the context of e-Government, since their suggestions and contributions may considerably influence decisions taken by public administrations. Specifically, we attempt to answer this research question: What are eGovernment organizational implications in the back office and in the interaction with citizens due to Information Technologies diffusion? Using data from a survey on 1,206 Italian public administrations, we show how organizational changes are emerging, based on the overcoming of traditional bureaucratic organizational forms. The implications of these findings are also discussed.
\end{abstract}

Keywords: E-Government, extended government, back-office, organizational theory, public administrations, citizens.

\section{Introduction}

The process of Government reform is highly intertwined with the evolution of paradigms in technology usage. This has often led to a technology centric view of innovation in the public sector, promoting an underestimation of its organizational implications [1]. As a net result, the first waves of public investments in ICTs produced very limited value for final users. Expectations for technology usage in Public Administrations (PAs) are very high, but will the value be ever delivered? We are convinced that much will depend upon the ability of public organizations to understand and adapt to the changes that the use of Information Technology (IT) applications will require. It is thus paramount to clearly single out what are the practical challenges that public managers will have to face in terms of work 
organization, coordination and skill acquisition in order to effectively leverage IT applications in the innovation of their internal processes [2]. Therefore, challenged in the back office of the PAs have to be analyzed with an organizational lens.

One of the main challenges for e-government consists in the realization of organizational changes in order to exploit the whole potential of IT for enhancing operations $[3,4]$. On the one hand, public agencies need to reshape their back office procedures and their organizational structure since they necessitate to shift from hierarchical organizations to network centric organizations [5]. On the other hand, the necessity of communicating with citizens in order to understand their requirements and meet their requests is compulsory if a PA wants to achieve an efficient level of performance. This is the reason why public administrations would increasingly make use of new tools, such as blogs, wikis and online community for interacting with their final customer, the citizen. Indeed, in an online community people share common interests, they are highly involved in the discussion topic and they are able to provide useful benefits for PAs in the definition of new interventions and policies [6].

This paper, exploratory in nature, has the aim of understanding e-government changes in the back office, given the more and more IT usage in PAs. Specifically, we use an organizational perspective. Grounding on the aspects mentioned above, the practical research question that this article intends to address is: What are egovernment organizational implications in the back office and in the interaction with citizens due to the IT diffusion?

We structure the reminder of this paper as follows. Section 2 provides definitions of the e-Government. Section 3 presents the theoretical background about organizational theories, while section 4 contains the discussion of the main findings. Finally, section five contains some concluding remarks and an indication for possible future research directions.

\section{E-Government}

PAs are lagging behind enterprises in the usage of ICTs for conducting their backoffice activities. Only a small number of PAs are incorporating the Information and Communication Technologies (ICTs) for automating their activities. To tackle this diffusion delay, especially in the last years, several initiatives have been launched to increase the e-Government phenomena [7, 8, 9]. Given that in this paper we are dealing with e-Government and there is some confusion in the e-Government definition, we try to explain the meaning of this concept. Indeed, in literature there are different definitions of e-Government. To better understand this concept, we provide in table 1 a set of definitions used by researchers.

As can be seen analyzing definitions contained in table 1, the common theme behind these definitions is that e-government takes into account the automation or computerization of existing paper-based procedures that will prompt new institutional and operational features, new managerial skills, new abilities of defining adequate policies, new capabilities of planning activities to conduct, new aptitudes to increase the citizens' involvement in public activities. Indeed, with the availabilities of new ICTs, combined with the organizational changes and the new competences creation, PAs have to overcome operational, institutional, managerial and strategic barriers. 
Table 1. E-government definitions

\begin{tabular}{ll}
\hline Source & Definition \\
\hline European Commission & $\begin{array}{l}\text { E-Government: is defined as the use of information and } \\
\text { communication technologies in public administrations } \\
\text { combined with organizational change and new skills in } \\
\text { order to improve public services and democratic } \\
\text { processes and strengthen support to public policies. }\end{array}$ \\
Baum and Di Maio, 2000 & $\begin{array}{l}\text { The e-government is the continuous optimization of } \\
\text { service delivery, constituency participation and } \\
\text { governance by transforming internal and external } \\
\text { relationships through technology, the Internet and new } \\
\text { media. } \\
\text { E-Government refers to the use by the general } \\
\text { government (including the public sector) of electronic } \\
\text { technology (such as Internet, intranet, extranet, databases, } \\
\text { decision support systems, surveillance systems and } \\
\text { wireless computing) that have the ability to transform } \\
\text { relations within the general government (bodies) and } \\
\text { between the general government and citizens and } \\
\text { businesses so as to better deliver its services and improve } \\
\text { its efficiency. } \\
\text { The term "e-government" focuses on the use of new } \\
\text { information and communication technologies (ICTs) by } \\
\text { governments as applied to the full range of government } \\
\text { functions. In particular, the networking potential offered } \\
\text { by the Internet and related technologies has the potential } \\
\text { to transform the structures and operation of government. } \\
\text { The use of information technology to free movement of } \\
\text { information to overcome the physical bounds of } \\
\text { traditional paper and physical based systems. }\end{array}$ \\
OECD, 2001 & $\begin{array}{l}\text { The use of technology to enhance the access to and } \\
\text { delivery of government services to benefit citizens, } \\
\text { business partners and employees. }\end{array}$ \\
Baharul, K.M., 2002 &
\end{tabular}

Moreover, PAs have to be aware of the existence of barriers that have to overcome when they decide to abandon the traditional activities for activities that require the usage of ICTs. A list of possible barriers that PAs have to consider when decide to shift from the traditional "government" to the "e-government" is provided in table 2.

As can be seen in the table 2, barriers to e-government can be grouped in three main categories: the institutional/operational, the managerial and the policy planning. The first one, the institutional/organizational category, considers all barriers related to the infrastructure features and the internal competencies in order to support operations. Indeed, it considers barriers related to costs in changes technology and infrastructure, the necessity of disposing resources to support internal operations, the suggestion of innovative solutions in order to innovate the "traditional" PAs and also the necessity of policy guidelines, which usually lack in the PAs. The second one, the 
managerial category, refers to managerial competences in order to manage the shift between the government and the e-government. In fact, in order to enable this shift, managerial competences for managing large-scale IT projects are required and also managerial competences in order to coordinate all managerial levels: from top to middle managers. Furthermore, managerial competences are important in order to manage the relationship not only with internal workers but also with possible external oppositions. Finally, managerial competences are important for enabling the share of information and data among departments. The third one, the policy/planning category, refers to the fact that today PAs lack in coordination among departments and in strategic planning, given that they do not follow a medium/long term horizon planning. Furthermore, public administrations lack in continuity of policy and programs and any policy guideline is absent. Finally, the PAs underestimate the contribution that the citizens could start to provide in the policy and programs definitions. Indeed, people were traditionally considered as consumers of contents instead of producer of contents, but nowadays they are becoming active producers of contents abandoning the role of passive Internet users. Thus, in case a PA would start to use more frequently the IT and would be active also online, it could beneficiate from the people comments, information and suggestions.

Table 2. Barriers to e-government (Source: United Nations, DPEPA, ASPA)

\begin{tabular}{|c|c|c|}
\hline Institutional/Operational & Managerial & Policy/Planning \\
\hline $\begin{array}{l}\text { Technology and } \\
\text { infrastructure costs/factors }\end{array}$ & $\begin{array}{l}\text { Lack of capacity to manage } \\
\text { large-scale IT projects }\end{array}$ & $\begin{array}{l}\text { Lack of coordination } \\
\text { and/or strategic planning }\end{array}$ \\
\hline $\begin{array}{l}\text { Lack of resources to support } \\
\text { operations }\end{array}$ & $\begin{array}{l}\text { Lack of conviction of top or } \\
\text { middle managers }\end{array}$ & $\begin{array}{l}\text { Opposition } \\
\text { professional or union } \\
\text { interests }\end{array}$ \\
\hline $\begin{array}{l}\text { Lack of innovative } \\
\text { incentives in public sector }\end{array}$ & $\begin{array}{l}\text { Management expectations } \\
\text { vs. management realities }\end{array}$ & $\begin{array}{l}\begin{array}{l}\text { Absence of policy } \\
\text { guidelines }\end{array}\end{array}$ \\
\hline $\begin{array}{l}\text { Organizational/cultural } \\
\text { dichotomies }\end{array}$ & $\begin{array}{l}\text { Doubts and resistance by } \\
\text { leadership }\end{array}$ & $\begin{array}{l}\text { Organizational/cultural } \\
\text { dichotomies }\end{array}$ \\
\hline Lack of institutional support & $\begin{array}{l}\text { Opposition by professional } \\
\text { or union interests }\end{array}$ & $\begin{array}{l}\text { Local governments and } \\
\text { municipalities if left far } \\
\text { behind become } \\
\text { bottlenecks }\end{array}$ \\
\hline $\begin{array}{l}\text { Information } \\
\text { mismanagement, reluctance } \\
\text { among departments, misuse } \\
\text { of sensitive data }\end{array}$ & $\begin{array}{l}\text { Information management, } \\
\text { reluctance to share among } \\
\text { departments, misuse of data }\end{array}$ & $\begin{array}{l}\text { Lack of } \\
\text { comprehensiveness } \\
\text { continuity of policies and } \\
\text { programs }\end{array}$ \\
\hline $\begin{array}{l}\text { Absence of policy } \\
\text { guidelines }\end{array}$ & $\begin{array}{l}\text { Obsolete legal framework to } \\
\text { innovate and incorporate }\end{array}$ & $\begin{array}{lr}\text { Lack } & \text { of } \\
\text { comprehensiveness } & \text { and } \\
\text { continuity } & \text { of } \\
\text { policies/programs } & \end{array}$ \\
\hline
\end{tabular}

The previous barriers are faced by all public administrations nowadays. Nevertheless, they are trying to overcome these barriers, even if it is difficult given cultural, technological and organizational settings. In order to understand how the 
organization has to change, in the following section we propose the framework provided by Hurst (1995) [10] and following reviewed by Daft (2004) [11], which shows what types of changes are necessary in order to leave the traditional organizational schemes. It is applied to the enterprise context, but we believe that it can be also applied to the public context.

\section{Organizational Theories}

The ability of managing IT in an information society, not only in the private sector, but also in the public sector, is becoming increasingly important. We are going through a period where organizations that adopt a network approach are always more frequent [12]. Effectively, public agencies have the necessity to adopt a network approach in order to reach high levels of collaboration, commitment and participation. Traditionally, the back office of an organization was organized as bureaucracies: the environment was perceived as predictable, stable and the role of the manager was of marginal importance [13]. The concept of bureaucracy included several concepts such as standardization of labour, hierarchy and strict rules [14]. In such a context, for allowing a shift from the bureaucracy to the network-oriented organization, from a close to an open system and from institutions to communities, organizational structure has to be changed [15].

IT plays an important role in the organizational redefinition, since it is considered a key factor, even though it is not the only important factor to take into account when the organizational evaluation is performed [16, 17]. Indeed, numerous factors influence the structure of an organization. Daft (2004) [11] distinguishes two types of factors that may influence the organizational efficiency: the structural factors and the contextual factors. The former indicates the internal features of an organization and provides a measure for comparing different organizations. It includes formalization, specialization, hierarchy of authority, centralization and professionalism. Whilst the latter characterizes the whole organization also beyond the physical organizational boundaries, including organizational size, the technology, the environment, organizational goals and organizational structure. It is worthwhile to remind that managers of a PA have to monitor all these factors in the supporting of the egovernment. However, they are not enough. Specifically, managers have to consider the rise of new organizational design approaches, in order to cope with the shift from a bureaucratic organization to a network organization where learning approach, communication, participation and coordination are the main aspects that distinguish the e-government implementation.

Searching the organizational features that characterize a network-oriented organization, the framework provided by Hurst (1995) [10] and following reviewed by Daft (2004) [11] seems the most appropriate. It contains the main distinctive elements useful to promote communication and collaboration in order to increase organizational capabilities. In particular, it shows the main elements that characterize the shift between the mechanical system design to the natural system design, called network-oriented organization, in a private organization (Figure 1). We expect that the same will happen in the public sector. Specifically, changes are following described. 


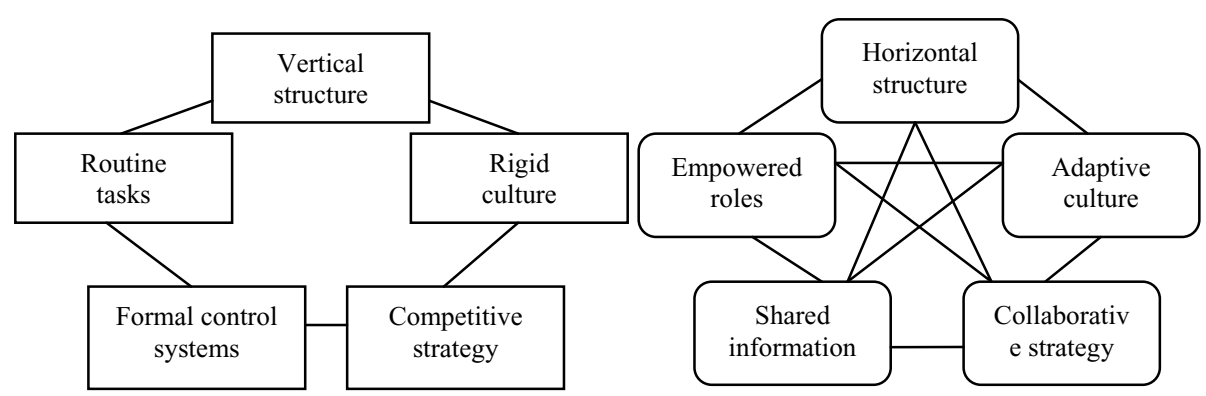

Fig. 1. Organizational design approaches $[10,11]$

From vertical to horizontal structure. Traditionally, the most common way to organize activities consisted in grouping them together according to their similarities, from the bottom to the top. Commonly there were no collaboration among departments and vertical hierarchy was the main coordination mechanism. Nevertheless, this structure is effective only in a stable environment. Since the PAs are experiencing a period of continuous changes and the environment in which they operate is turbulent and dynamic, a shift from a vertical structure to an horizontal structure, where boundaries of departments are not so strict as before and where collaboration is widespread, is needed.

From routine tasks to empowered roles. Traditional organizations were characterized by employees with specialized tasks, while in the dynamic social system people have roles redefined and adjusted. In fact, employees are encourage to share their knowledge and collaborate together in order to achieve a common goal. Also, in the natural system design, people employed in the PAs have to work and listen customers' needs and requests, going beyond the physical organizational barriers.

From formal control systems to shared information. In a mechanical system design, large and complex organizations were characterized by a big distance between top leaders and workers in the technical core. Formal systems usually are implemented in order to manage the growth of the information amount that has to be processed. Conversely, in network oriented organizations information provides a different purpose. Ideas and information are shared throughout the organization and also there are open lines of communication with citizens through the Web 2.0 tools, as forums, blogs and online communities [18].

From competitive to collaborative strategy. In traditional organizations the strategy was formulated by top managers and was imposed on the organization and on all people that operated in the organization. On the contrary, in network oriented organization, informed and empowered workforce contribute to the development of the strategy, since they identify needs and solutions given their linkage with citizens ideas and suggestions [19].

From rigid to adaptive culture. A rigid organization is characterized by fixed cultural values, ideas and practices which could be detrimental in case a rapid change in the environment occurs. This situation is very common in a society that is increasingly dependent on the IT development speed. Indeed, the network oriented communities stand for openness, continuous adaptation and changes. People in the 
organization have to be aware that their contribution is not enough for the success of the organization itself, so that they need to interact with actors beyond organizational boundaries. In addition, public managers have to face with work reorganization, promotion of coordination and skill acquisition in order to effectively leverage web 2.0 applications in the organizational management [20].

By looking to these two organizational design approaches and even if the literature contains several studies that analyze how the IT influence the organizational structure, there are questionable findings about the organizational implications in the back office of a public organization and in the relationship with citizens, given that the widely IT diffusion and the Web 2.0 applications are gaining increasingly popularity in the interaction with people.

\section{The Organizational Change Inside Public Administrations: Evidence from an Italian Survey}

The analysis of organizational changes in the PAs was conducted through a survey that we send to Italian PAs every year. In this research study we have considered data of 2007, 2008 and 2009. The data used for this study are the output of a survey carried out every year on a population of around 1206 PAs located in Piedmont, a north-west region of Italy. The survey is part of the policy intelligence activities carried out by the ICT Observatory of the Piedmont Region. In the following sub-sections we provide two analysis attempting to provide a link between the organizational theories explained in section 3 and data we gathered. First, we look at the back-office organizational changes. Second, we look at changes in the relationship between the PAs and the citizens, allowed by the availability of new ICTs.

In paragraph 4.1 we investigate changes in the back office by looking at four main variables: the existence of an Information and Telecommunication (IT) office; the existence of an IT manager; the existence of an IT manager or and IT office; the percentage of disperser workers. Whereas in paragraph 4.2 we investigate the relationship between citizens and public administrations by analyzing the existence of a web site in the public administrations, and the newsletter, surveys and RSS tools used by public administrations in order to interact with citizens.

First of all, we decided to investigate on the existence of an Information and Telecommunication (IT) office, of an IT manager or at least one of them given that we believe that these indicators provide an explanation of the IT adoption levels that the PAs have reached, showing how the PAs have an adaptive culture and tend to become horizontal organizations by integrating all functions together through the IT usage. This aspect is also underlined by the percentage of disperser workers that are employed in PAs, since they provide a clear indication of how the organization does not limit its activities inside its physical boundaries. Then, we asked to PAs about the existence of a web site in order to understand the level of openness of PAs themselves and to monitor the shift between the formal control system to the shared information system followed. Finally, the existence of tools that enable a relationship and an opinion exchange between citizens and PAs are investigated in order to figure out how organizations follow collaborative strategies instead of competitive strategies, how adopt a model based on shared information instead of control system and how 
pursue an adaptive culture instead of a rigid culture. Nevertheless we were not able to measure the shift from the routine tasks to empowered roles.

Specifically, table 3 reports the linkage between the variable measured and the organizational change associated. All variables were operationalized by a dummy variable.

Table 3. Variable used and organizational changes associated

\begin{tabular}{|c|c|c|c|c|c|}
\hline Variable & $\begin{array}{c}\text { From } \\
\text { vertical to } \\
\text { horizontal }\end{array}$ & $\begin{array}{l}\text { From } \\
\text { routine } \\
\text { tasks to } \\
\text { empowered } \\
\text { roles }\end{array}$ & $\begin{array}{c}\text { From } \\
\text { control } \\
\text { systems to } \\
\text { shared } \\
\text { information }\end{array}$ & $\begin{array}{c}\text { From } \\
\text { competitive } \\
\text { strategy to } \\
\text { collaborative } \\
\text { strategy }\end{array}$ & $\begin{array}{c}\text { From rigid } \\
\text { culture to } \\
\text { adaptive } \\
\text { culture }\end{array}$ \\
\hline IT office & & & & & $\mathrm{X}$ \\
\hline IT manager & & & & & $X$ \\
\hline $\begin{array}{l}\text { IT manager } \\
\text { of IT office }\end{array}$ & & & & & $\mathrm{X}$ \\
\hline $\begin{array}{l}\% \text { disperser } \\
\text { workers }\end{array}$ & $\mathrm{X}$ & & & & $\mathrm{X}$ \\
\hline Website & & & $X$ & & $\mathrm{X}$ \\
\hline Newsletters & & & $X$ & $\mathrm{X}$ & $X$ \\
\hline Surveys & & & $X$ & $\mathrm{X}$ & $\mathrm{X}$ \\
\hline RSS & & & $\mathrm{X}$ & $\mathrm{X}$ & $X$ \\
\hline
\end{tabular}

\subsection{Changes in the Back Office}

Few studies have analyzed the organizational changes in the PAs and how they are evolving in a period when the ICT are widely adopted and the Web 2.0 is increasing its diffusion. In back office functions, the roles are undergoing a transformation and new IT capabilities are required, given that the capability of IT to automate the aspects related to the supervision of work has radically changed the allocation of power (Scott Morton, 1991) [121]. Technological and organizational changes are necessary to cope with the diffusion of the ICT and its increasing usage. PAs will be able to manage this trend only by implementing significant changes. Something has been done, but with limited results. This is the reason why we are exploring how PAs are managing these changes and what organizational and technological changes are applying in their internal processes and in the interaction with citizens. More skilled human capital is required in order to manage the wide usage of the ICT and new organizational models are needed if the shift between the "traditional government" and the e-Government has to occur. Specifically, looking at the internal organization of the PAs interviewed, we have chosen 4 indicators. We believe that these indicators well represent the changes that the PAs have to start to apply in order to manage the transaction between the traditional government and the e-Government. In particular, the four indicators (figure 2) are: 1) The existence of an IT office; 2) The existence of an IT manager; 3) The existence of an IT manager or IT office; 4)The percentage of disperser workers. 


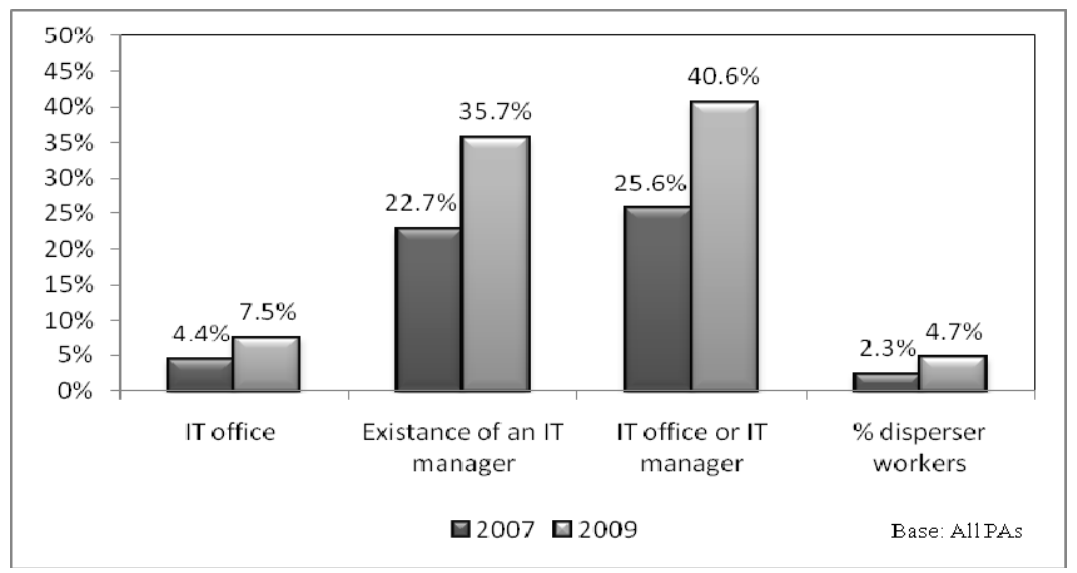

Fig. 2. Back-office organization (Source: ICT Observatory of Piedmont)

These four indicators give evidence of a general process of restructuring the backoffice which is strictly connected with investments in new IT systems, in the definition of an IT manager and in changes of the workforce management. We decided to show only data of 2007 and 2009, given that it is a growing trend between these two periods. By looking at data, the percentage of PAs that have an IT office is increased between the 2007 and the 2009from the $4.4 \%$ to the $7.5 \%$. Furthermore, the management capabilities are becoming strongly important, given that the existence of a formal figure, such as the IT manager, given an indication of how the back office functions has been going through a redefinition. Indeed, in 2009 the $35.7 \%$ of the PAs has an IT manager, in contrast with the $22.7 \%$ in 2007 . Finally, as explained in the previous paragraph, given that empowered roles are needed, an adaptive culture is required and a collaborative strategy is necessary, organizational changes occur also in the workforce management. Particularly, as shown in figure 2, the dispersed workers are also rising (2.3\% in 2007 and 4.7\% in 2009), underling two main facts: first, a restructure of the workers management is occurring; second, the IT has been used more heavily, given that the disperser workers have to interact with the people that work inside the boundaries of the PAs.

However, it is still not clear how fast these technological and organizational changes will occur in the near future.

\subsection{Changes in the Relationship Citizen-Public Administrations}

Individuals do not live in isolation, but belong to groups. Thanks to Web 2.0 tools the size and the geographical dispersion of social groups is increasing. Nevertheless, not only the relationships between individuals are changing, but also new forms of management are gradually moving from a logic of command and control to another one of connection and collaboration, both internal and external to the public sector organization (Friedman, 2007) [14], the collaboration between people is increasing and Web 2.0 is emerging as primal aspect of human nature in the use of the World Wide Web. Related to this, new virtual areas where people can meet and 
communicate are emerging - blogs, wikis, social networks, online communities - and the need to manage and control the information flow is becoming recently a central issue (Osimo, 2008) [1]. Indeed, the process of knowledge development and communication on the web is strongly influenced by the level of collaboration, participation and interaction among people, which is principally obtained through their interpersonal communication (Wenger et al., 2002) [23]. Thus, the increased engagement of citizens and the wider use of ICT tools result in four main potential of innovation in the interaction of citizens with the government: 1) broader value added to government from citizens thanks to data mining of social networking sites; 2) reengagement of younger citizens in policy making processes as they are more likely to use social networking sites to express opinions; 3) increased numbers of citizen viewpoints represented in policy formation through use of social networking site analysis; 4) increased levels of interaction between citizens and government in policymaking.

The conducted research shows how PAs provide new services to citizens in order to increase their participation to the public activities. First of all, the presence of a search engine on the web site of PAs is increasing during the years. In 2007, the $27 \%$ of the PAs had a search engine, in 2008 it reached the $38 \%$, and finally it was $45 \%$ in the 2009 (figure 3). This means that not only PAs are using more widely the ICT, but also the citizens are appreciated these new instruments.

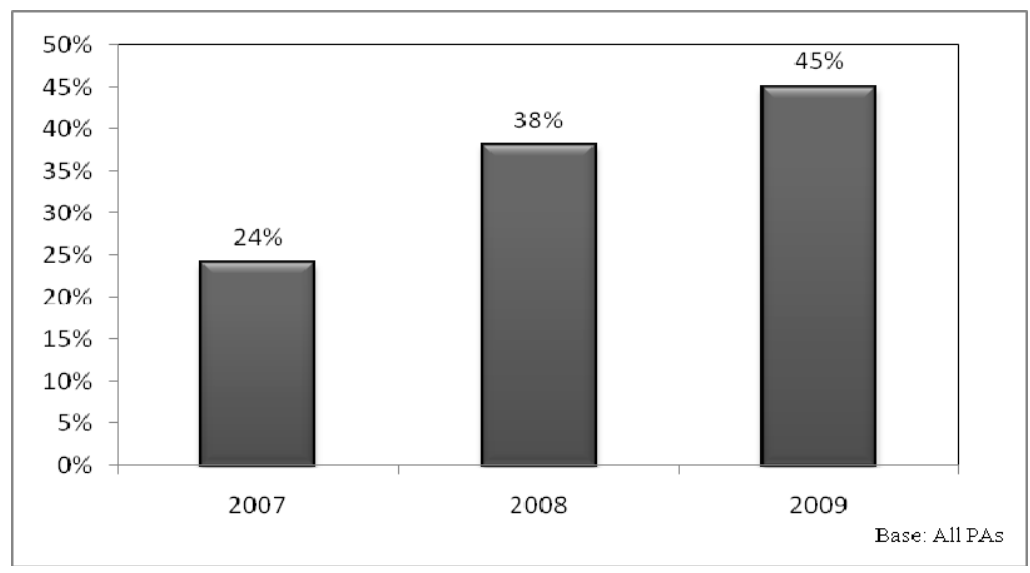

Fig. 3. Search engine existence on the web site (Source: ICT Observatory of Piedmont)

By looking to data gathered, it emerges how the new tools offered by the PAs for the interaction with the citizens are becoming more diffused. Specifically, we have investigate the diffusion of the newsletter, surveys and RSS (most commonly expanded as Really Simple Syndication) (figure 4).

Three main finding emerge: 1) the diffusion of the newsletters, a regularly distributed publication generally about one main topic that is of interest of public administrations, is increasing; 2) the surveys' delivery, usually used by public administrations in order to analyze the citizens' position about initiatives and decisions of the public administrations, is more frequent than in the past; 3) RSS, a 


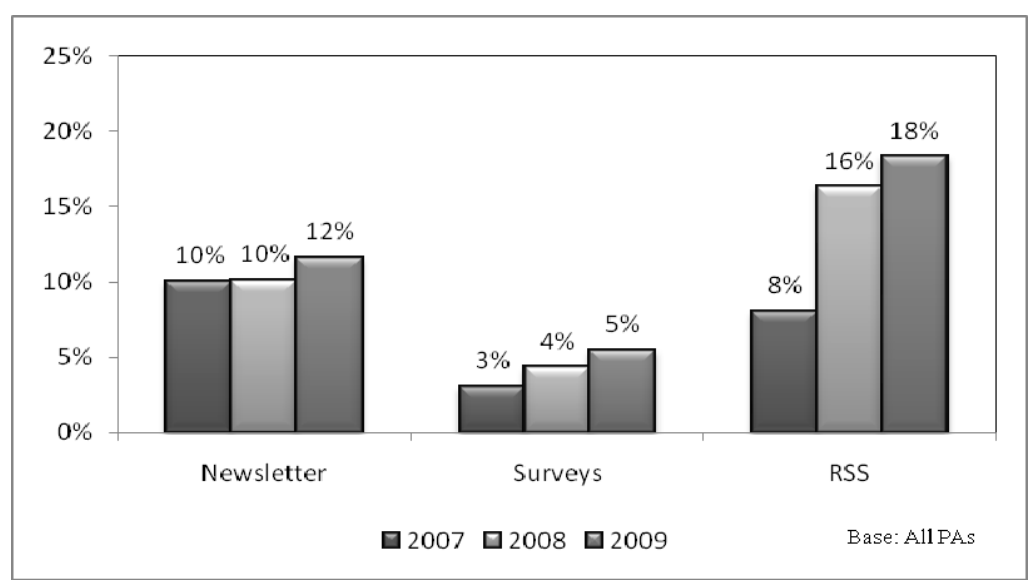

Fig. 4. Tools for the interaction between the citizens and the public administrations (Source: ICT Observatory of Piedmont)

family of web feed formats used to publish frequently updated works - such as blog entries, news headlines, audio, and video - in a standardized format (Wikipedia, 2010) [24], was used only by the $10 \%$ of PAs in 2007, and it has reached the $18 \%$ in 2009 . Even though the adoption of these tools is enhanced in the last three years, the percentages are still low (only the 12\% have a newsletter, the 5\% conduct analysis survey and the $18 \%$ has a RSS). Nevertheless, we believe that the rising of the adoption trends of these tools indicate how the PAs are changing, are using more widely the ICT and are becoming to be aware about the important of the interaction with the citizens.

\section{The Organizational Change Inside Public Administrations: Evidence from an Italian Survey}

The transition from the "traditional government" to the e-Government has been recently investigated, but without considering both the usage of the ICT and the organizational transforms that are needed in public administrations in order to manage the changes that are occurring in such a context. As mentioned in the introduction, the first waves of public investments in ICTs produced very limited value for final users. Nevertheless, expectations on technology usage in the PAs are still very high.

Specifically, in this paper we have analyzed the evolution of organizational models in PAs and the increased interaction between citizens and PAs. By data analysis, we have found two main findings. First, evidence of a general process of restructuring in the back-office of public administrations is shown. New IT systems are adopted and changes in the workforce management emerge. Moreover, new forms of management are gradually moving from a logic of command and control to another one of connection and collaboration, both internally and externally to the public sector's organizations. Second, the PAs are favouring the usage of new ICT tools in order to 
involve citizens in policy making processes, increase numbers of citizen viewpoints represented in policy formation and increase levels of interaction between citizens and government in policymaking. The combined effect of such changes may represent a first hint of a paradigm shift towards the creation of an extended governance model where institutional boundaries are blurring and new management styles are emerging [25]. Such shift, of course, need to be further investigated in order to be better framed and understood in all its facets.

From a policy viewpoint, policy makers could further enhance the engagement of citizens in policy making processes and they would encourage radical changes in the organizational models. Indeed, a major awareness about the organizational changes that would occur in PAs is needed and a cultural change is compulsory if improvements in activities conducted by PAs are expected.

This study contains two main limitations that will be investigate in future research studies. First, the next survey will be constructed by analyzing more in depth the organizational changes that are occurring in public administrations. Second, other variables will be used for analyzing the adoption level of technologies reached by public administrations, such as the usage of social networks for interacting with the citizens and the intranet usage to securely share any part of an organization's information or network operating system within the organization.

Concluding, this paper shows how the Internet and the ICTs are more widely adopted by PAs than in the past, organizational changes are emerging, the transition from the "traditional government" to the e-Government starts to occur, even though these changes and the adoption rates are still in an infancy stage given that public administrations have to learn how to answer timely to the external inputs.

\section{References}

1. Osimo, D.: Web 2.0 in Government: Why and How? JRC Scientic and Technical Reports (2008)

2. Gareis, K., Osimo, D.: Benchmarking Regional Performance in the Information Society: Turning It into Practice. In: The 5th Annual Conference of the Association of Internet Researchers, Brighton (2004)

3. Kang, I., Lee, K.C., Lee, S., Choi, J.: Investigation of online community voluntary behavior using cognitive map. Computers in Human Behavior, 111-126 (2007)

4. Simon, H.A., Thompson, V.A., Smithburg, D.W.: Public Administration (3rd printing). Transaction Publishers, New Brunswick (1991)

5. Bannister, F.: Dismantling the silos: extracting new value from IT investments in public administration. Information Systems Journal, 65-84 (2001)

6. Kim, A.J.: Community building on the Web: Secret strategies for successful online communities. Peachpit Press, Berkeley (2000)

7. United Nations, DPEPA, ASPA: Benckmarking E-government: A Global PerspectiveAssessing the UN Member States (2002),

http: / / www. unpan1.un.org/intradoc/groups / public/documents / un/ unpan021547.pdf

8. European Commission: The Role of eGovernment for Europe's Future (2003), http: / / ec.europa.eu/information_society/eeurope/2005/doc/all_ about/egov_communication_en.pdf 
9. Chen, H., Brandt, L., Gregg, V., Traunmüller, R., Dawes, S., Hovy, E., Macintosh, A., Larson, C.A.: Digital Government E-Government Research, Case Studies, and Implementation. Springer Series: Integrated Series in Information Systems, Vol. 17 (2007)

10. Daft, L.R.: Organization Theory and Design, 8th edn. Thomson South-Western (2004)

11. Hurst, D.K.: Crisis and Renewal: Meeting the Challenge of Organizational Change. Business School Press, Boston (1995)

12. Castells, M.: The Rise of The Network Society. Blackwell Publishing, Malden (2000)

13. Tetenbaum, T.J.: Shifting Paradigms: From Newton to Chaos. Organizational Dynamics, 21-32 (1998)

14. Yan, L.: Innovation on Temporary Post-Disaster Reconstruction Organization Structure and Management Model. Journal of East China University of Science and Technology (2009)

15. Agranoff, R., McGuire, M.: Big Questions in Public Network Management Research. Journal of Public Administration Research Theory, 295-326 (2011)

16. Thompson, J.D.: Organizations in action. McGraw-Hill, New York (1967)

17. Welp, Y., Urgell, F., Aibar, E.: From Bureaucratic Administration to Network Administration? An Empirical Study on E-Government Focus on Catalonia. Public Organization Review 7, 299-316 (2007)

18. Grandori, A., Soda, G.: Inter-firm Networks: Antecedents, Mechanisms and Forms. Organization Studies 16(2), 183-214 (1995)

19. Huxham, C.: Collaborative Capability: an Intraorganizational Perspective on collaborative Advantage. Public Money\&Management 13(3), 21-28 (1993)

20. Fedele, M., Moini, G.: Cooperare conviene? Intercomunalità e politiche pubbliche. Rivista italiana di Politiche Pubbliche 1, 71-98 (2006)

21. Morton, S.: The Corporation of the 1990s - Information Technology and Organizational Transformation. Oxford University Press, New York (1991)

22. Friedman, T.: The world is flat 3.0: A brief history of the twenty-first century. Picador, New York (2007)

23. Wenger, E., McDermott, E., Snyder, W.: Cultivating Communities of Practice: A Guide to Managing Knowledge. Harvard Business School Press, Boston (2002)

24. Wikipedia (2010), http: / / en.wikipedia.org/wiki/RSS

25. Löffler, E.: Why co-production is an important topic for local. IDeA Community of Practice on Co-Production Government (2009) 